\title{
Studi Karakteristik Morfometrik Ikan Julung-Julung (Hemiramphus Archipelagicus) Di Daerah Intertidal Teluk Ekas
}

\author{
I Gde Suryawan $^{1)}$, Mahrus $^{2)}$, Karnan $^{3)^{*}}$ \\ ${ }^{1)}$ Mahasiswa Pendidikan Biologi FKIP Universitas Mataram \\ 2) ${ }^{3}$ Dosen Pendidikan Biologi FKIP Universitas Mataram \\ Universitas Mataram, Jalan Majapahit No. 62 Mataram \\ *Email: karnan.ikan@unram.ac.id
}

\begin{abstract}
ABSTRAK
Penelitian ini bertujuan untuk mengetahui karakteristik morfometrik dan meristik ikan julung-julung di Teluk Ekas, Lombok Timur. Sampel penelitian berjumlah 165 ikan yang di tangkap pada daerah intertidal dengan metode swept area menggunakan pukat pantai (beach seine) di tiga stasiun. Karakteristik morfologi yang terlihat dengan jelas pada ikan julungjulung ini yaitu memiliki rahang bawah dengan warna merah pada ujungnya dan memiliki ukuran yang jauh lebih panjang jika dibandingkan dengan rahang atasnya. Hasil pengukuran karakteristik morfometrik menunjukkan bahwa ikan julung-julung yang terdapat pada daerah intertidal perairan Teluk Ekas merupakan ikan muda (juvenile) dengan frekuensi panjang total (PT) tertinggi terdapat pada ukuran 13,1-15 cm. Kesimpulan dari penelitian ini menunjukkan bahwa ikan julung-julung di daerah intertidal Teluk Ekas memiliki karakteristik morfometrik yang hampir sama dengan ikan julung-julung pada umumnya.
\end{abstract}

Kata-kata kunci: Ikan Julung-Julung, Karakteristik, Meristik, Morfometrik

\begin{abstract}
This research intended to know the morphometric and meristic characteristic of jumping halfbeak at Ekas Bay, East Lombok. The sample of this research consisted of 165 fishes which caught at intertidal zone using swept area method with beach seine in three stations. The morphological characteristic which can be seen clearly on jumping halfbeak has lower jaw with red tip and longer than its upper jaw. The results of measurement of morphometric characteristic proved that jumping halfbeak at intertidal zone of Ekas Bay were young fish (juvenile) total length highest frequency on range of 13,1-15 cm. The conclusion of this research is jumping halfbeak at the intertidal zone of Ekas Bay has the similar characteristic morphometric to the general one.
\end{abstract}

Keywords: Characteristic, Jumping halfbeak, Meristic, Morphometric 


\section{PENDAHULUAN}

Teluk Ekas merupakan salah satu perairan di Lombok yang memiliki potensi perikanan tinggi. Hal ini dikarenakan Teluk Ekas memiliki hamparan padang lamun yang luas (Karnan et al., 2016). Sebelumnya, Aslianti et al. (2008) melaporkan bahwa Teluk Ekas juga memiliki potensi sebagai tempat pembudidayaan ikan dan memiliki karakteristik biota laut yang memadai. Disamping itu Teluk Ekas juga berdekatan dengan Selat Lombok yang menghubungkan massa air dengan Samudera Pasifik menuju Samudera Hindia sehingga teluk ini menampung banyak suplai nutrien untuk ekosistem pesisir daerah ini (Tim Proyek Carrying Capacity BRKP, 2004). Salah satu zona yang terdapat pada kawasan pesisir yaitu zona pasang surut (intertidal zone), yang terlihat jelas pada kawasan perairan di Teluk Ekas. Menurut Pariwono (1985) perkataan pasang-surut (pasut) pada umumnya dikaitkan dengan proses naik turunnya paras laut (sea level) secara berkala yang ditimbulkan oleh adanya gaya tarik dari benda-benda angkasa.

Karnan et al. (2016) melaporkan komoditas ikan julung-julung memiliki jumlah yang sangat melimpah pada daerah intertidal Teluk Ekas. Ikan ini memiliki harga pasaran yang dapat bersaing dengan harga ikan target lainnya. Selain itu, Julius et al. (2011) melaporkan bahwa ikan julung-julung sangat diminati oleh pasar dan memiliki harga yang tetap stabil. Hal ini mendorong nelayan Teluk Ekas berusaha untuk mendapatkan hasil tangkapan maksimal, meskipun sering mengabaikan aspek biologi dan lingkungan dari ikan julung-julung tersebut.
Aktivitas penangkapan ikan julungjulung tersebut dapat mempengaruhi perubahan struktur populasi dari sumberdaya ikan julung-julung. Hal ini dapat mengakibatkan jumlah ikan yang ada di perairan menjadi berkurang jumlahnya. Taeran et al. (2013) melaporkan bahwa penurunan kelimpahan stok julung-julung di perairan diduga akibat terjadinya peningkatan intensitas eksploitasi terhadap sumber daya julung-julung. Di satu pihak sumberdaya hayati laut cenderung tidak ekonomis lagi jika dieksploitasi untuk terus-menerus memenuhi kebutuhan masyarakat yang jumlahnya terus meningkat dengan pesat, sedangkan di lain pihak ketersediaan sumberdaya alam terus menurun akibat degradasi ekosistem laut yang tidak terkendali (Reppie et al., 2011). Pengelolaan yang didasarkan pada informasi biologis sangat diperlukan dalam upaya mempertahankan kelestarian ikan julung-julung, untuk itu dilakukan penelitian mengenai studi karakteristik morfometrik ikan julung-julung di daerah intertidal Teluk Ekas.

\section{BAHAN DAN METODE}

Jenis penelitian ini adalah deskriptif eksploratif, yang menggambarkan keadaan atau suatu fenomena dengan cara mengetahui hal-hal yang berhubungan dengan obyek yang diteliti. Penelitian ini dilaksanakan di Perairan Teluk Ekas, Lombok Timur. Pengambilan sampel dilakukan pada daerah intertidal yang terdapat pada kawasan perairan Teluk Ekas.

Pengambilan sampel dilakukan di tiga titik pemantauan (stasiun) dengan mempertimbangkan kondisi substrat perairan, persentase tutupan lamun, dan 
lokasi penangkapan ikan oleh nelayan. Pengumpulan data dilakukan dalam periode Mei-Juni 2016. Sampel ikan dikoleksi dengan metode swept area menggunakan pukat pantai (beach seine). Spesifikasi pukat pantai yang digunakan adalah: ukuran panjang $50 \mathrm{~m}$, lebar $2 \mathrm{~m}$ dengan mata jaring sayap berukuran 1 inci, 0,75 inci, dan 0,6 inci serta mata jaring tengah berukuran 0,25 inci. Pengambilan sampel dilakukan sebanyak 4 (empat) kali dengan mempertimbangkan fase bulan.

Ikan-ikan yang diperoleh dikumpulkan kedalam wadah yang sudah disediakan (ember atau kantong plastik). Ikan-ikan tersebut dipilah menurut jenisnya dan diambil jenis ikan julungjulung. Sampel ikan julung-julung yang diperoleh dibawa ke laboratorium program studi Biologi FKIP Universitas Mataram untuk dilakukan pengukuran karakteristik morfometrik (Tabel 3.1). Teknik analisis data yang digunakan dalam penelitian ini menggunakan analisis statistik deskriptif, meliputi rataan dan simpangan baku dari hasil pengukuran yang dilakukan.

\section{Hasil dan Pembahasan}

\section{Karakteristik morfometrik ikan julung- julung}

Terdapat 21 macam pengukuran karakteristik morfometrik (Tabel 3.1). Tabel 3.1 tersebut menyampaikan kisaran, nilai rata-rata dan simpangan baku (SD) pada masing-masing karakteristik morfometrik ikan julung-julung. Kisaran pengukuran karakteristik morfometrik pada Tabel 3.1 menunjukkan bahwa ukuran ikan julung-julung yang terdapat pada daerah intertidal perairan Teluk Ekas bervariasi. Variasi ukuran panjang dari masing-masing karakteristik morfometrik yang diperoleh ditunjukkan dengan nilai simpangan baku (SD). Nilai simpangan baku tertinggi terdapat pada ukuran panjang total dengan nilai $\mathrm{SD} \pm 2,316$ dan nilai simpangan baku yang terendah terdapat pada ukuran panjang dasar sirip ventral dengan nilai $\mathrm{SD} \pm 0,075$.

Tabel 3.1 Hasil perhitungan karakteristik morfometrik 165 ikan julung-julung

\begin{tabular}{|c|c|c|c|c|}
\hline No. & Karakteristik morfometrik & $\begin{array}{c}\text { Kisaran } \\
(\mathrm{cm})\end{array}$ & $\begin{array}{c}\text { Rata-Rata } \\
(\mathrm{cm})\end{array}$ & $\begin{array}{c}\text { Simpangan } \\
\text { baku (SD) }\end{array}$ \\
\hline 1. & Panjang total (PT), & $5,1-19,0$ & 13,338 & $\pm 2,316$ \\
\hline 2. & Panjang standar (PS), & $4-15,4$ & 10,178 & $\pm 1,774$ \\
\hline 3. & Panjang kepala (PK), & $0,4-3,4$ & 2,162 & $\pm 0,499$ \\
\hline 4. & Panjang sebelum sirip dorsal (PSSD), & $1,9-11,5$ & 7,647 & $\pm 1,499$ \\
\hline 5. & Panjang sebelum sirip ventral (PSSV), & $0,5-9$ & 5,872 & $\pm 1,300$ \\
\hline 6. & Panjang sebelum sirip anal (PSSA), & $1,2-11,9$ & 7,716 & $\pm 1,617$ \\
\hline 7. & Tinggi kepala (TK), & $0,2-1,4$ & 0,861 & $\pm 0,194$ \\
\hline 8. & Tinggi badan (TB), & $0,3-2$ & 1,247 & $\pm 0,293$ \\
\hline 9. & Tinggi pangkal ekor (TPE), & $0,2-0,9$ & 0,536 & $\pm 0,119$ \\
\hline 10. & Panjang batang ekor (PBE), & $0,3-1,7$ & 1,198 & $\pm 0,258$ \\
\hline 11. & Panjang dasar sirip dorsal (PDSD), & $0,4-2,5$ & 1,501 & $\pm 0,310$ \\
\hline 12. & Panjang dasar sirip anal (PDSA), & $0,3-1,9$ & 1,213 & $\pm 0,273$ \\
\hline 13. & Panjang dasar sirip ventral (PDSV), & $0,1-0,4$ & 0,188 & $\pm 0,075$ \\
\hline 14. & Panjang dasar sirip pectoral (PDSP), & $0,1-0,7$ & 0,367 & $\pm 0,091$ \\
\hline 15. & Panjang sirip ekor bagian atas (PSEA) & $0,2-2,1$ & 1,317 & $\pm 0,327$ \\
\hline 16. & Panjang sirip ekor bagian tengah (PSET), & $0,1-1$ & 0,643 & $\pm 0,166$ \\
\hline 17. & Panjang sirip ekor bagian bawah (PSEB), & $0,4-2,6$ & 1,790 & $\pm 0,385$ \\
\hline 18. & Panjang moncong (PM), & $0,2-1,5$ & 0,715 & $\pm 0,194$ \\
\hline 19. & Diameter mata (DM), & $0,2-0,9$ & 0,616 & $\pm 0,121$ \\
\hline 20. & Jarak mata ke tutup insang (JMTI), & $0,3-1,4$ & 0,859 & $\pm 0,196$ \\
\hline 21. & Jarak antara dua mata (JAM), & $0,2-1,1$ & 0,702 & $\pm 0,153$ \\
\hline
\end{tabular}




\section{Sebaran frekuensi panjang ikan}

Gambar 3.1 menyajikan ukuranukuran panjang total ikan julung-julung di daerah intertidal Teluk Ekas. Sebaran panjang total ikan tersebut dimulai pada kelas 51-70 mm sampai dengan 171-190 $\mathrm{mm}$. Sebaran panjang total yang tertinggi terletak pada kelas 131-150 mm dengan jumlah 60 ekor ikan, sedangkan sebaran panjang total yang terendah terletak pada kelas 71-90 mm dan 171-190 $\mathrm{mm}$ dengan jumlah 2 ekor ikan.

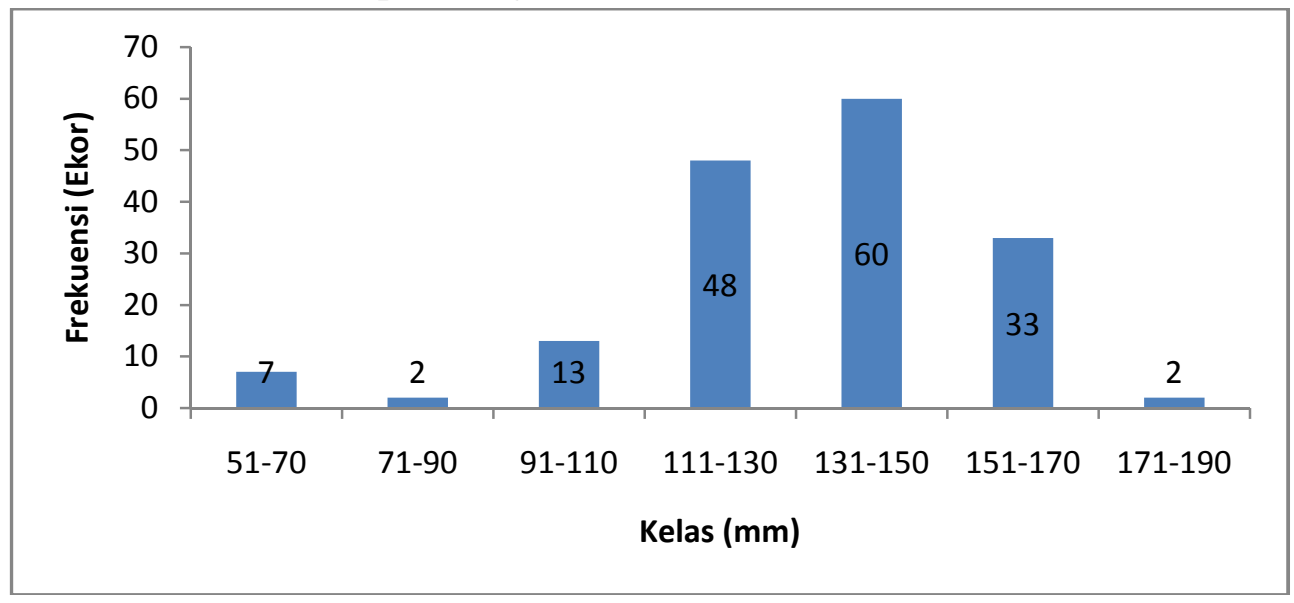

Gambar 3.1 Sebaran frekuensi panjang total ikan julung-julung

\section{Karakteristik morfometrik ikan julung- julung}

Ikan julung-julung yang ditemukan pada daerah intertidal Teluk Ekas memiliki panjang total yang tidak jauh berbeda dengan yang ada di perairan pantai utara Aceh, Fadhil et al. (2016) melaporkan kisaran panjang 10-14,2 cm dengan rerata panjang $12,5 \mathrm{~cm}$ dan Triyono et al. menemukan panjang ikan julung-julung di Perairan Selat Alas sebesar 17,57 cm. Pada lokasi lain Julius et al., (2011) mendapatkan sebaran panjang ikan julungjulung dengan rata-rata panjang total 16,7 $\mathrm{cm}$ sampai dengan $18 \mathrm{~cm}$ di Kepulauan Sangihe pada ekosistem terumbu karang. Panjang total maksimum ikan julungjulung dapat mencapai $45 \mathrm{~cm}$, dan umumnya mencapai $30 \mathrm{~cm}$ (Genisa, 1999; Carpenter (1999).

Jika dicermati lebih jauh, panjang total ikan julung-julung yang berada pada daerah intertidal Teluk Ekas dan pada lokasi lain masih merupakan ikan kecil yang sedang mengalami pertumbuhan dan perkembangan. Hal ini sejalan dengan Triyono et al. (2013) yang melaporkan bahwa ikan julung-julung jantan matang gonad pada ukuran 18,77 cm (kisaran panjang $18,7-18,83 \mathrm{~cm}$ ), dan betina adalah $18,51 \mathrm{~cm}$ (kisaran panjang 18,48-18,55 $\mathrm{cm})$. Selain itu, Varghese (2005) juga melaporkan bahwa hanya 50\% sebaran panjang pada ikan famili Hemirampidae sudah mencapai dewasa terletak pada selang panjang $12,5-14,5 \mathrm{~cm}$ dan $100 \%$ pada sebaran panjang 19,5-22,5 cm. Perhitungan frekuensi panjang total (Gambar 3.1) ikan julung-julung di daerah intertidal Teluk Ekas pada penelitian ini membuktikan bahwa ikan julung-julung yang terdapat di lokasi merupakan ikan muda (juvenile) yang belum dewasa dan belum matang gonad. Sejalan dengan Phil dan Heemstra, E (2004) yang melaporkan bahwa ukuran juvenil famili ikan 
Hemirampidae yaitu dengan panjang total berkisaran antara 9-12 cm.

Banyaknya ikan julung-julung yang berukuran juvenil pada daerah intertidal perairan Teluk Ekas ini juga membuktikan bahwa ekosistem padang lamun yang terdapat pada daerah intertidal sangat berperan penting sebagai daerah asuhan, tempat berlindung, dan mencari makan. Hal ini sesuai dengan Latuconsina et al. (2011) melaporkan bahwa tingkat ikan juvenil tertinggi terletak pada daerah dengan kerapatan vegetasi lamun yang tinggi. Adi (2007) juga melaporkan peningkatan jumlah larva dan juvenil ikan dibarengi dengan jumlah peningkatan kerapatan lamun, hal ini dapat dijelaskan dengan fungsi lamun untuk memberikan tempat berlindung, tempat mencari makan dan daerah asuhan.

\section{KESIMPULAN}

Ikan julung-julung di daerah intertidal Teluk Ekas memiliki karakteristik morfometrik yang hampir sama dengan ikan julung-julung pada umumnya.

\section{DAFTAR PUSTAKA}

Adi, W. 2007. Komposisi Dan Kelimpahan Larva Dan Juvenil Ikan Yang Berasosiasi Dengan Tingkat Kerapatan Lamun Yang Berbeda Di Pulau Panjang, Jepara. Jurnal Sumberdaya Perairan 1: 711.

Aslianti, T., B. Slamet dan G. S. Prasetya. 2008. Aplikasi Budidaya Kerapu Bebek, Cromileptes altivelis di Teluk Ekas Kabupaten Lombok Timur. Balai Besar Riset Perikanan Budidaya Laut Gondol PO Box. 140. Singaraja 81101, Bali, Hal. 2.
Carpenter, K. E. 1999. The Living Marine Resources Of The Western Central Pasific. FAO Species Identification Guide For Fishery Purpose. ISSN 1020-6868, 2149-2196.

Fadhil, R., Z. A Muchlisin dan W. Sari. 2016. Hubungan Panjang-Berat Dan Morfometrik Ikan JulungJulung (Zenarchopterus dispar) Dari Perairan Pantai Utara Aceh. Jurnal Ilmiah Mahasiswa Kelautan dan Perikanan Unsyiah 1: 146159.

Genisa, A. S. 1999. Pengenalan Jenis-Jenis Ikan Laut Ekonomi Penting Di Indonesia. Oseana XXIV: 17-38.

Julius. F., Wuaten, E. Reppie, L. Ivor dan Labaro. 2011. Kajian Perikanan Tangkap Ikan Julung-Julung (Hyporhamphus affinis) di Perairan Kabupaten Kepulauan Sangihe. Jurnal Perikanan dan Kelautan Tropis VII-2: 80-86.

Karnan, L. Japa, dan A. Raksun. 2016. Struktur Komunitas Sumberdaya Ikan Padang Lamun di Teluk Ekas Lombok Timur. Jurnal Bilogi Tropis 16: 80-89.

Latuconsina, H., R. A. Rappe, dan M. N. Nessa. Asosiasi Ikan Baronang (Siganus canaliculatus Park, 1797) Pada ekosistem Padang Lamun Perairan Teluk Ambon Dalam. Ambon : Universitas Darussalam.

Pariwono, J. I. 1989. Pasang-Surut. Jakarta : LIPI.

Phil, dan E. Heemstra. 2004. Coastal Fishes Of Shoutern Africa. Africa : Pearl Print.

Reppie, E., E. P. Sitanggang dan J. Budiman. 2011. Pendugaan Potensi dan Musim Penangkapan Ikan Julung-Julung (Hemiramphus sp.) 
Berdasarkan Hasil Tangkapan Soma Giop di Perairan Selat Bangka, Kabupaten Minahasa Utara. Pacific Journal Regional Board of Research North Sulawesi 1: 1010-1014.

Taeran, I., M. S. Baskoro, A. A. Taurusman, D. R. Monintja dan Mustaruddin. 2013. Prioritas Strategi Pengelolaan Perikanan Giob Yang Berkelanjutan Di Kayoa, Halmahera Selatan. UNKHAIR: Fakultas Perikanan Ilmu Kelautan.

Triyono, H., K. S. Bestynar dan N. a. Prabasiwi. 2013. Aspek Biologi Dan Perikanan Ikan Julung-Julung
(Hemiramphus far) Yang Didaratkan Di Pangkalan Pendaratan Ikan (PPI) Tanjung Luar Lombok Nusa Tenggara Barat. Jakarta: STP.

Tim Proyek Carrying Capacity Badan Riset Kelautan dan Perikanan. 2004. Daya Dukung Kelautan dan Perikanan. Badan Riset Kelautan dan Perikanan. ISBN 979-97572-82, 108-118.

Varghese, A. S. 2005. Systematics And Biology Of Fishes Of The Family Hemiramphidae of Cochin Coast.Thesis. The Cochin University Of Science And Technology. 